Article

\title{
Brittle Failure of Nanoscale Notched Silicon Cantilevers: A Finite Fracture Mechanics Approach
}

\author{
Pasquale Gallo $1, *($ i) and Alberto Sapora $2, *(1)$ \\ 1 Department of Mechanical Engineering, Aalto University, P.O. Box 14100, FIN-00076 Aalto, Finland \\ 2 Department of Structural, Building and Geotechnical Engineering, Politecnico di Torino, \\ Corso Duca degli Abruzzi 24, 10129 Torino, Italy \\ * Correspondence: pasquale.gallo@aalto.fi (P.G.); alberto.sapora@polito.it (A.S.)
}

Received: 5 February 2020; Accepted: 25 February 2020; Published: 29 February 2020

Featured Application: The work provides an extremely useful method to predict the static failure of Micro- and Nano-Electromechanical Systems (MEMS, NEMS). The Finite Fracture Mechanics approach may have an enormous impact on the failure characterization of notched and cracked components in the field of nanodevices.

\begin{abstract}
The present paper focuses on the Finite Fracture Mechanics (FFM) approach and verifies its applicability at the nanoscale. After the presentation of the analytical frame, the approach is verified against experimental data already published in the literature related to in situ fracture tests of blunt V-notched nano-cantilevers made of single crystal silicon, and loaded under mode I. The results show that the apparent generalized stress intensity factors at failure (i.e., the apparent generalized fracture toughness) predicted by the FFM are in good agreement with those obtained experimentally, with a discrepancy varying between 0 and $5 \%$. All the crack advancements are larger than the fracture process zone and therefore the breakdown of continuum-based linear elastic fracture mechanics is not yet reached. The method reveals to be an efficient and effective tool in assessing the brittle failure of notched components at the nanoscale.
\end{abstract}

Keywords: finite fracture mechanics; nanoscale; silicon; brittle; notch; fracture; nanodevice

\section{Introduction}

Recent technological developments have enabled the fabrication of electronic devices with high-density integration. Small size components, e.g., at the nanometer scale, can be fabricated with different shapes including features such as notches and may have defects such as cracks [1,2]. These circumstances have brought problems commonly addressed by fracture mechanics and fatigue theory to a completely new scale level, raising several new questions, experimental challenges, but also attractive new scientific possibilities [3-5]. The demand for static and fatigue assessment of nanoscale components is increasing, on the one hand, and the validity of continuum-based approaches is questioned on the other. Indeed, at a very small scale, the simplification of a body as continuum and homogeneous may not hold, and the discrete nature of atoms should be considered [6-8]. Clarification of these aspects could not only bring enormous development in the field of nanotechnology, but macroscale could benefit as well, e.g., multi-scale modeling of fatigue with focus on short cracks and interaction with local micro-structure $[9,10]$, atomistic investigation of stresses, strains and grain boundaries [11], fracture properties of advanced materials [12,13], experimental evaluation of fatigue curve of microscale samples [14]. 
Several studies have recently quantified the small scale breakdown of continuum-based linear elastic fracture mechanics (LEFM) and have demonstrated that continuum-based methods are still valid at small scale if that limit is not reached [15-18]. The breakdown was expressed in terms of the ratio between the crack singular stress field length, which surprisingly is still characterizing the crack at a very small scale [19-21], and the fracture process zone. When this ratio is in the order of 4-5, continuum-based LEFM breaks down and the discrete nature of atoms cannot be ignored. Some researchers have gone at a further small size, and have tried to propose approaches that consider the atomic structures and would be valid at different scales. In this regard, it is worth mentioning those based on Griffith's criterion applied to single crystal silicon [22,23] and graphene [24], and more recently on averaged strain energy density concept [17]. On the other hand, as briefly mentioned earlier, when that limit is not reached, continuum-based approaches should be valid. This conclusion opens up a large number of possibilities in the field of nanotechnology since well-known tools could be extended to small scale for, e.g., nanoscale mechanical characterization, static/fatigue assessment of cracked or notched components $[14,25]$. For example, the continuum formulation of averaged strain energy density concept has been demonstrated to be valid for nanoscale notched-samples [26,27]. Similarly, by using the Theory of Critical Distances (TCD) [28,29], a fast and extremely simple method was proposed to evaluate with high accuracy the fracture toughness of single crystal silicon by using notched samples [30]. At small scales, indeed, the fabrication of pre-cracks is extremely difficult, since an atomic sharp crack is ideally necessary to obtain a reliable fracture toughness when dealing with brittle materials. Even for small values of the tip radius, the defect would behave as a notch and would result in an apparent fracture toughness [19,31]. In regard to the experimental challenges, it is also worth mentioning a recent study on experimental conditions affecting the measurement of the fracture toughness in elastic-plastic materials [32].

Among well-known fracture models, the Finite Fracture Mechanics (FFM) approach has several similarities with the methods mentioned before [33]. The FFM was originally proposed to deal with crack initiation in brittle material and to overcome the limitation of classical fracture mechanics, which assumes the pre-existence of a crack and deals only with its growth [34,35]. The FFM, instead, is a coupled criterion, i.e., it requires two conditions to be full-filled simultaneously: One based on a stress requirement and the other involving the energy balance. When these conditions are met, there is an instantaneous formation (or growth) of a crack of finite size (finite step). This assumption drastically re-defines the concept of crack growth, which becomes a structural parameter rather than a simple material constant. Over the past decades, the approach has been applied or extended successfully to a large variety of problems, both in static and fatigue, by considering different materials, features and loading conditions, e.g., to rounded V-notches made of ceramic, metallic and plastic materials [36,37], crack at interfaces and at bi-material junctions [38,39], 3-D failure onset from sharp V-notch edge [40], failure initiation at the atomic scale by means of molecular simulations [41], multiaxial loading conditions and notch sensitivity [42,43], moderate and large scale yielding regimes [44]. Furthermore, FFM predictions have been recently proved to be very close to those by the powerful cohesive zone model (CZM) in different research frameworks [45-48], so one can use FFM for preliminary sizing in structural design, letting the CZM for subsequent study refinements. By considering the advantages of the FFM approach and the similitude with other methods successfully applied to small scale specimens, it is worth investigating the validity of the FFM at the nanoscale. FFM would be, indeed, a very useful method for the brittle failure characterization of nanostructures.

By considering experiments available in the literature, the present paper verifies the applicability of the FFM approach at the nanoscale. At first, the analytical frame of FFM is presented; subsequently, recent experimental tests on nanoscale notched cantilevers, made of single crystal silicon, are briefly reviewed and presented; finally, the results are discussed. Only mode I loading condition and brittle fracture are considered. The work represents an additional proof that, when far from the small scale breakdown of continuum-based LEFM, classic concepts such as FFM can be employed successfully to characterize the fracture process of nanodevices. 


\section{Materials and Methods}

\subsection{Fundamentals of FFM Approach for Blunt V-Notches}

The FFM approach [35] assumes that a crack advances of a finite length $l$ when two criteria, one based on stress and the other on the energy balance, are full-filled simultaneously. The stress criterion requires that the average stress $\sigma_{y}(x)$ upon the crack advance $l$ is higher than the material tensile strength $\sigma_{u}$ :

$$
\int_{0}^{l} \sigma_{y}(x) \mathrm{d} x \geq \sigma_{u} l
$$

where $(x, y)$ is the Cartesian coordinate system centered at the notch root (Figure 1). The energy criterion ensures that the energy available for a crack increment $l$ is higher than the energy necessary to create the new fracture surface. Irwin's relationship allows expressing the requirement in the form

$$
\int_{0}^{l} K_{I}^{2}(c) \mathrm{d} c \geq K_{I c}^{2} l
$$

$K_{I}(c)$ and $K_{I c}$ being the stress intensity factor (SIF) related to a crack of length $c$ stemming from the notch root (Figure 1) and the fracture toughness, respectively. At incipient failure, Equations (1) and (2) coalesce into a system of two equations in two unknowns: The critical crack advancement $l_{c}$ and the failure load.

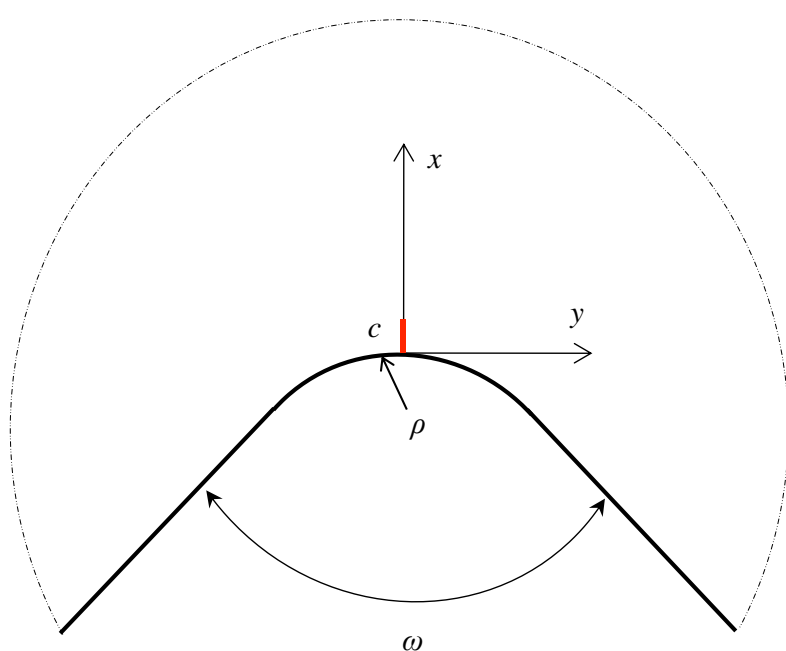

Figure 1. Blunt V-notch geometry: $c$ represent the length of a crack stemming from the notch tip.

Focusing on blunt V-notched geometries [37] and assuming the notch tip radius $\rho$ sufficiently small with respect to the notch depth $a$ (Figure 2), the stress field along the notch bisector can be expressed as [49]:

$$
\sigma_{y}(x)=\frac{K_{I}^{V, \rho}}{\left[2 \pi\left(x+r_{0}\right)\right]^{1-\lambda}}\left[1+\left(\frac{r_{0}}{x+r_{0}}\right)^{\lambda-\mu} \eta_{\theta}(0)\right]
$$

where $K_{I}^{V, \rho}$ is the apparent generalized (or notch) SIF, and

$$
r_{0}=\frac{\pi-\omega}{2 \pi-\omega} \rho .
$$

The parameters $\lambda, \mu$ and $\eta_{\theta}(0)$ depend on the notch amplitude $\omega$, and their values are reported in Table 1. Furthermore, supposing a crack of length $c$ sufficiently small with respect to the notch depth $a$ (Figures 1 and 2), the following relationship was proposed for the SIF $K_{I}$ [50]: 


$$
K_{I}(c)=\frac{\beta K_{I}^{V, \rho} c^{\lambda-0.5}}{\left[1+\left[\frac{r_{0}}{c}\left(\frac{\beta}{\alpha}\right)^{\frac{1}{1-\lambda}}\right]^{m}\right]^{\frac{1-\lambda}{m}}},
$$

where

$$
\alpha=1.12 \sqrt{\pi} \frac{\left[1+\eta_{\theta}(0)\right]}{(2 \pi)^{1-\lambda}}
$$

and $\beta, m$ are provided in Table 1.

Table 1. Dimensionless parameters used in the present analysis as a function of the notch amplitude $\omega$. See [37] as reference.

\begin{tabular}{cccccc}
\hline$\omega$ (deg) & $m$ & $\lambda$ & $\boldsymbol{\mu}$ & $\eta_{\boldsymbol{\theta}} \mathbf{( 0 )}$ & $\boldsymbol{\beta}$ \\
\hline 0 & 1.82 & 0.5000 & -0.5000 & 1.000 & 1.000 \\
33 & 1.45 & 0.5021 & -0.4515 & 1.035 & 1.005 \\
48 & 1.38 & 0.5040 & -0.4285 & 1.007 & 1.010 \\
59 & 1.35 & 0.5075 & -0.4105 & 0.9700 & 1.017 \\
68 & 1.34 & 0.5122 & -0.3950 & 0.9310 & 1.030 \\
150 & 1.22 & 0.7520 & -0.1624 & 0.2882 & 1.394 \\
\hline
\end{tabular}

Within brittle structural behavior, it is legitimate to suppose that failure takes place as soon as the apparent generalized SIF reaches its critical value $K_{I}^{V, \rho}=K_{I c}^{V, \rho}$, usually termed as apparent generalized fracture toughness. As expected, FFM can be implemented by inserting Equations (3) and (5) into Equations (1) and (2), respectively, and integrating. Simple analytical manipulations lead to the following two coupled equations:

$$
\frac{K_{I c}^{V, \rho}}{\sigma_{u} r_{0}^{1-\lambda}}=f\left(\bar{l}_{c}\right),
$$

and

$$
r_{0} \frac{\sigma_{u}^{2}}{K_{I c}^{2}}=\frac{h\left(\bar{l}_{c}\right)}{f^{2}\left(\bar{l}_{c}\right)}
$$

where the functions $f, h$ rising from the integration procedure are [37]:

$$
\begin{gathered}
f\left(\bar{l}_{c}\right)=\frac{\bar{l}_{c}(2 \pi)^{1-\lambda}}{\left[\frac{\left(\bar{l}_{c}+1\right)^{\lambda}-1}{\lambda}\right]+\eta_{0}(0)\left[\frac{\left(\bar{l}_{c}+1\right)^{\mu}-1}{\mu}\right]} \\
h\left(\bar{l}_{c}\right)=\frac{\bar{l}_{c}}{\int_{0}^{\bar{l}_{c}} \frac{\bar{c}^{(2 \lambda-1)} \beta^{2}}{\left\{1+\left[\left(\frac{\beta}{\alpha}\right)^{\frac{1}{1-\lambda}} \frac{1}{\bar{c}}\right]^{m}\right\}^{\frac{2(1-\lambda)}{m}}}} \\
\{\bar{c}
\end{gathered}
$$

$\bar{l}_{c}=l_{c} / r_{0}$ and $\bar{c}=c / r_{0}$. The system of Equations (7) and (8) is solved numerically through a simple MATLAB ${ }^{\circledR}$ code: For a given structure, after extracting $l_{c}$ from Equation (8), the apparent generalized fracture toughness can be estimated through Equation (7). 


\subsection{Review of Recent In Situ Experimental Tests}

The analytical frame presented in Section 2.1 is verified against experimental tests recently published by Gallo et al. [30]. That work was originally proposed to characterize the fracture toughness of silicon by using the TCD. In detail, in situ fracture tests were carried out in a transmission electron microscope (TEM). Four specimens were considered, made of single crystal silicon, and fabricated by a focused ion beam (FIB) processing system. The fabrication process and orientation are simplified in Figure 2 while the detailed procedure is provided in [30]. Geometry and example of a sample are presented in the lower-half of Figure 2, whilst Table 2 gives the geometrical details.

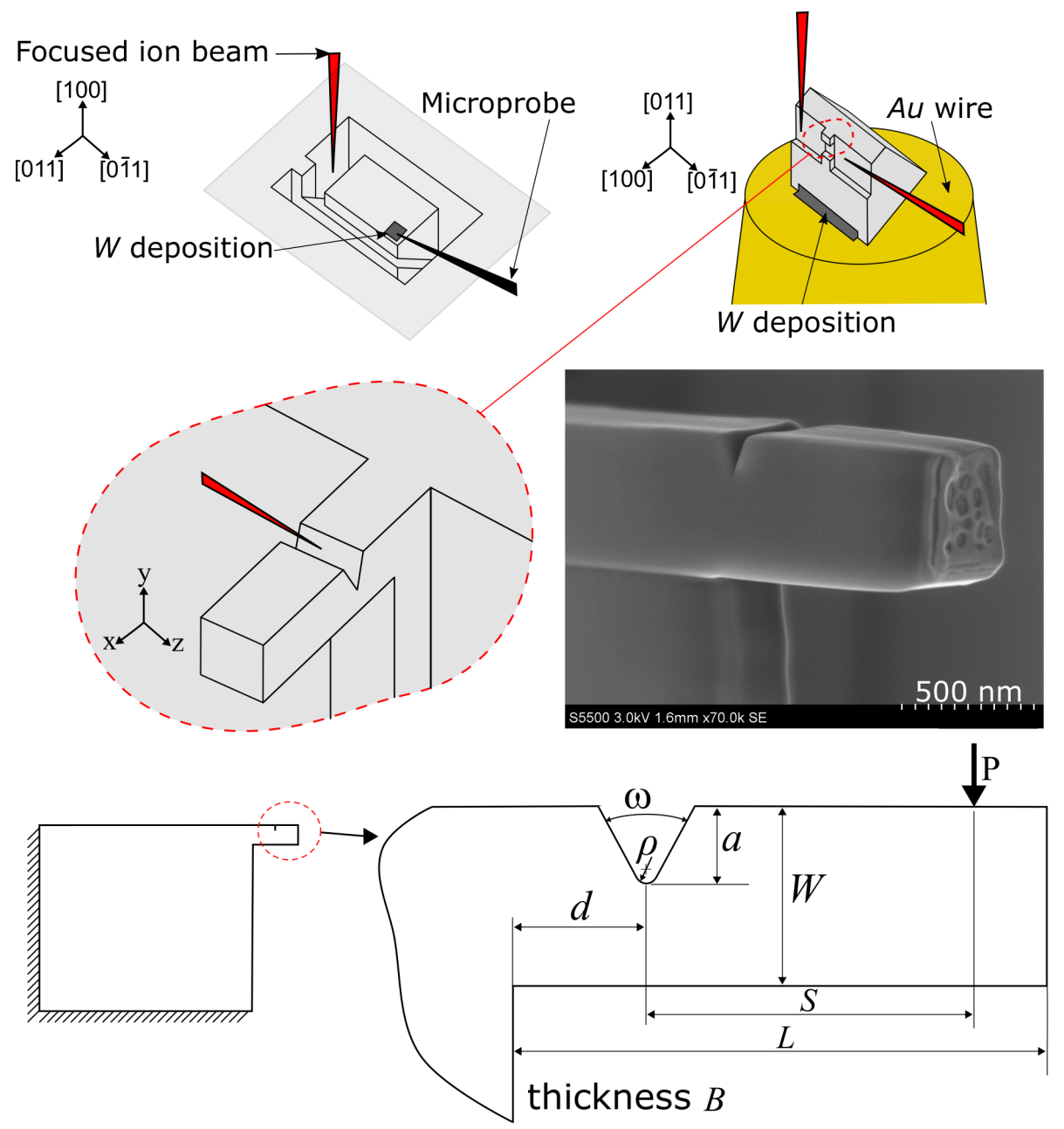

Figure 2. Example of main steps of fabrication process, orientation, final sample (specimen 2) and geometrical details of the blunt V-notched nano-cantilevers. At first, a block is carved from bulk single crystal silicon plate; later, the block is positioned on a gold wire and the nano-cantilever is cut; the notch is finally introduced by focused ion beam (FIB).

Table 2. Geometrical parameters of the blunt V-notched nano-cantilevers (see Figure 2).

\begin{tabular}{cccccccccc}
\hline Sample & $\boldsymbol{\omega}(\mathbf{d e g})$ & $\boldsymbol{\rho} \mathbf{( \mathbf { n m } )}$ & $\boldsymbol{a}(\mathbf{n m})$ & $\boldsymbol{d}(\mathbf{n m})$ & $\boldsymbol{S}(\mathbf{n m})$ & $\boldsymbol{L}(\mathbf{n m})$ & $\boldsymbol{B}(\mathbf{n m})$ & $\boldsymbol{W}(\mathbf{n m})$ & $\mathbf{P}_{\mathbf{f}}(\boldsymbol{\mu N})$ \\
\hline 1 & 33 & $\approx 10$ & 155 & 217 & 837 & 1307 & 494 & 502 & 45.33 \\
2 & 48 & $\approx 14$ & 161 & 96 & 682 & 1019 & 529 & 544 & 84.80 \\
3 & 59 & $\approx 20$ & 179 & 119 & 651 & 1201 & 484 & 495 & 65.11 \\
4 & 68 & $\approx 6$ & 144 & 87 & 875 & 1252 & 454 & 456 & 30.84 \\
\hline
\end{tabular}


The samples have different notch radii $\rho$ and opening angles $\omega$ measured at the best of authors capability by means of scanning electron microscope (SEM). It is worth noting that the samples have an $a / W$ ratio varying between 0.3 and 0.36 , while $\rho / a$ varies between 0.07 and 0.11 . Experimental mechanical characterization at the considered scale gave an ultimate strength $\sigma_{u}$ of $13.9 \mathrm{GPa}$, and a fracture toughness $K_{I c}$ of approximately $1 \mathrm{MPa}^{0.5}$. The latter is determined experimentally by employing the TCD [30], pre-cracked samples [19] and even by considering the atomic scale by means of molecular simulations $[15,22]$. The fracture tests are realized by pushing the nano-cantilevers towards an indenter which is able to detect the applied load. Table 2 summarizes the load at failure, $P_{f}$, as obtained in [30], which should be consulted for additional details on experimental procedures and loading device.

\section{Results}

The analytical frame developed in Section 2.1 is fully applicable provided the low ratios $a / W$ and $\rho / a$ presented in the previous section (Table 2). By recalling the apparent fracture toughness of a sharp V-notch defined according to [35]

$$
K_{I c}^{V}=\lambda^{\lambda}\left[\frac{(2 \pi)^{2 \lambda-1}}{\beta^{2} / 2}\right]^{1-\lambda} \frac{K_{I c}^{2(1-\lambda)}}{\sigma_{u}^{1-2 \lambda}},
$$

the dimensionless apparent generalized fracture toughness is plotted in Figure 3 versus the dimensionless notch root radius $\rho / l_{c h}$, where $l_{c h}=\left(K_{I c} / \sigma_{u}\right)^{2} \approx 5.18 \mathrm{~nm}$ is the so called "Irwin's length" (see Section 2.2 for the mechanical properties). In addition to the geometries considered in the present work, Figure 3 also includes the results for the opening angle $\omega=0^{\circ}$ and $\omega=150^{\circ}$, as references. When $\rho \rightarrow 0$, the fracture toughness ratio correctly tends to 1 since $K_{I c}^{V, \rho}$ is approaching the value of the sharp $(\rho=0)$ V-notch $K_{I c}^{V}$. Given a fixed value of the normalized notch root radius, the ratio increases as the the opening angle $\omega$ decreases, i.e., the lower the notch amplitude, the higher the influence of the radius.

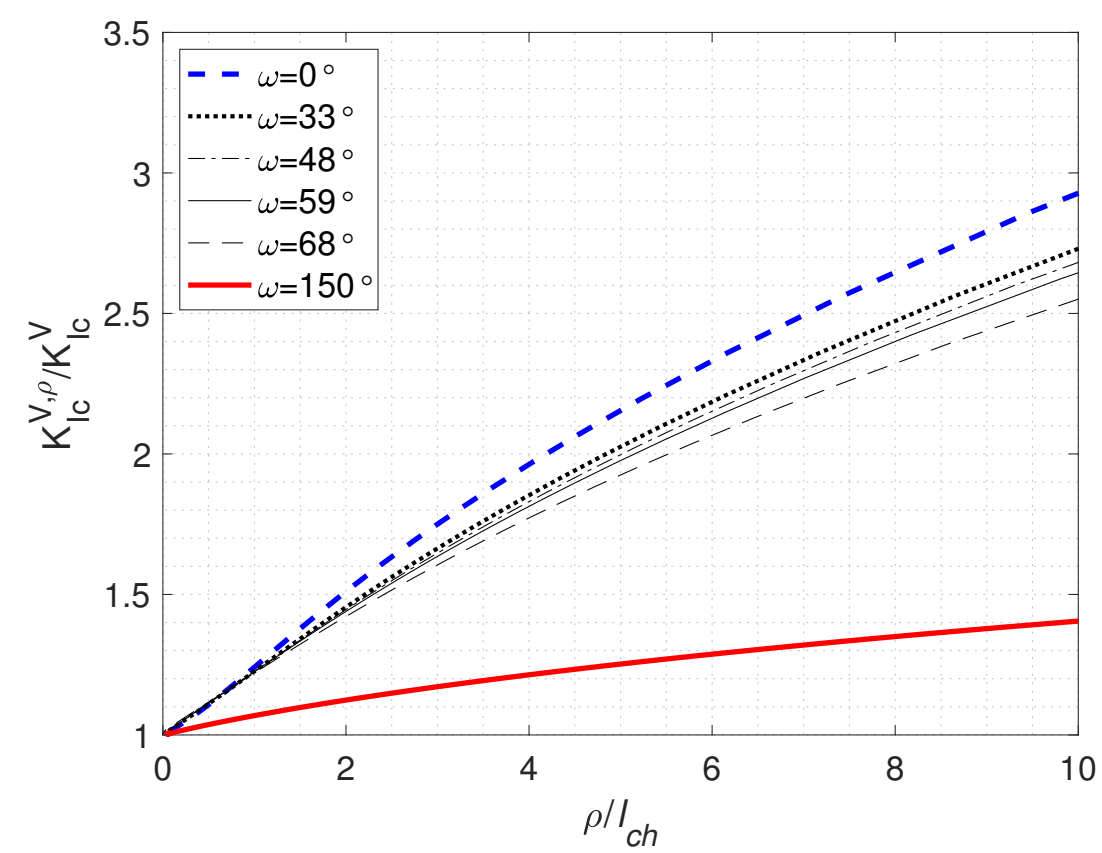

Figure 3. Dimensionless apparent generalized fracture toughness versus dimensionless notch root radius for the opening angles of the nano-cantilever considered in Section 2.2. For the sake of clarity, two additional opening angles are added as references, i.e., $\omega=0^{\circ}$ and $\omega=150^{\circ}$. Irwin's length $l_{c h}=\left(K_{I c} / \sigma_{u}\right)^{2} \approx 5.18 \mathrm{~nm}$. 
The dimensionless crack extension is plotted in Figure 4. As $\rho \rightarrow 0$, the geometry reverts to the sharp V-notch case, with the curves approaching the values provided by the function [35]:

$$
l_{c}^{V}=\frac{2}{\lambda \beta^{2}(2 \pi)^{2(1-\lambda)}} l_{c h},
$$

which leads to a decreasing crack length for higher notch amplitudes. As $\rho$ increases the element becomes smoother, and each function converges to the asymptotic value $l_{c}=2 / \pi\left(\frac{K_{I c}}{1.12 \sigma_{u}}\right)^{2}$. The most significant deviations from the sharp case are again generally observed as the notch amplitude decreases. Semi-analytical values of crack advancements are also reported in Table 3, showing that for the current geometries all the crack advances were within $10 \%$. Dimensionless values of the notch root radius are reported as well.

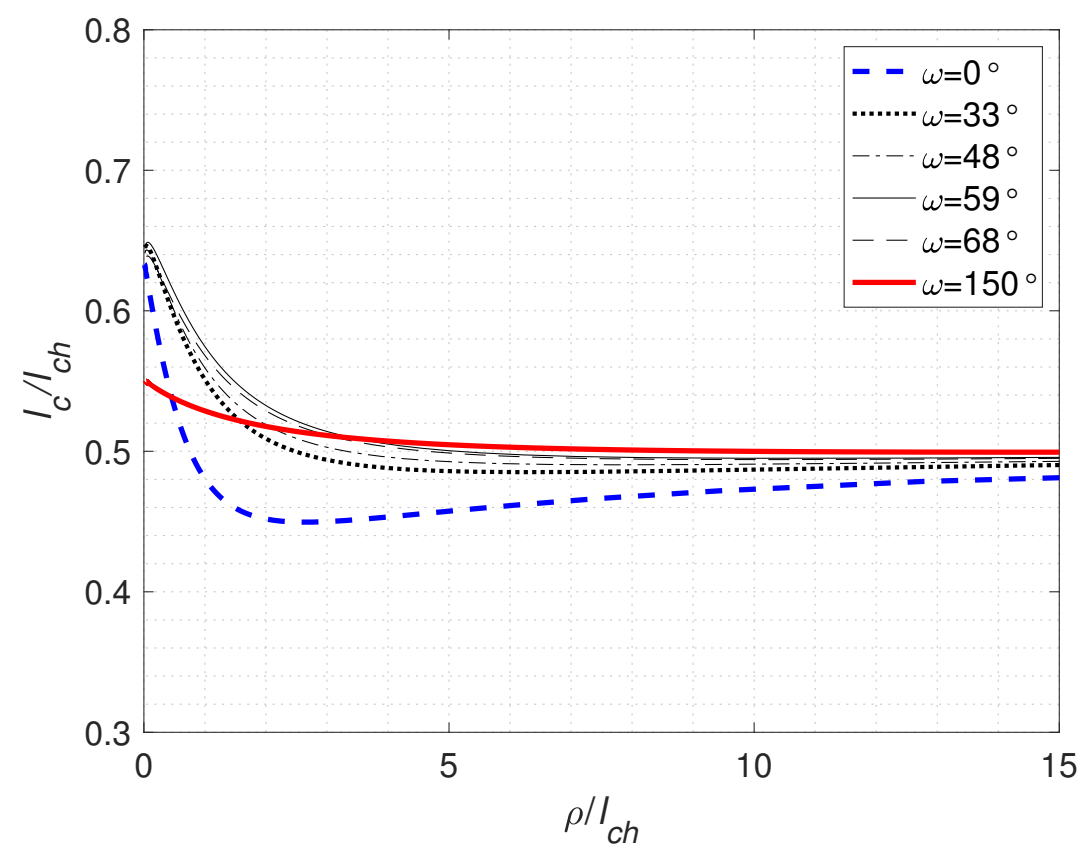

Figure 4. Critical crack advancement versus notch root radius normalized by Irwin's length, $l_{c h}=$ $\left(K_{I c} / \sigma_{u}\right)^{2} \approx 5.18 \mathrm{~nm}$.

Table 3. Critical crack advancement for the geometries under consideration. The reference crack advancement related to a sharp notch provided by Equation (12) is also reported. Irwin's length is equal to $l_{c h}=\left(K_{I c} / \sigma_{u}\right)^{2} \approx 5.18 \mathrm{~nm}$.

\begin{tabular}{ccccc}
\hline$\omega(\operatorname{deg})$ & $\rho / l_{c h}$ & $l_{c}^{V}(\mathrm{~nm})$ & $l_{c}(\mathrm{~nm})$ & $l_{c} / l_{c}^{V}$ \\
\hline 33 & 1.97 & 3.27 & 2.64 & 0.806 \\
48 & 2.67 & 3.25 & 2.62 & 0.807 \\
59 & 3.90 & 3.23 & 2.60 & 0.805 \\
68 & 1.22 & 3.17 & 2.83 & 0.894 \\
\hline
\end{tabular}

Finally, the theoretical FFM estimations based on Figures 3 and 4 are compared with experimental values. In order to obtain the experimental apparent fracture toughness, the stress at the notch root $\sigma_{\max }=\sigma_{y}(0)$ at incipient failure must be evaluated through FEM analysis. Indeed, numerical simulations were already carried out in [30] to study the local stress state and are here exploited, for the sake of simplicity. The experimental values of $K_{I c}^{V, \rho}$ can be then easily obtained from Equation (13): 


$$
K_{I c}^{V, \rho} \exp .=\sigma_{\max } \frac{\left(2 \pi r_{0}\right)^{1-\lambda}}{\left[1+\eta_{\theta}(0)\right]}
$$

and results are summarized in Table 4 and Figure 5. It is clear that FFM accurately estimates the apparent generalized fracture toughness with a negligible error of $4.7 \%$ in the worst case $\left(\omega=33^{\circ}\right)$, and an excellent agreement in the best case $\left(\omega=48^{\circ}\right)$.

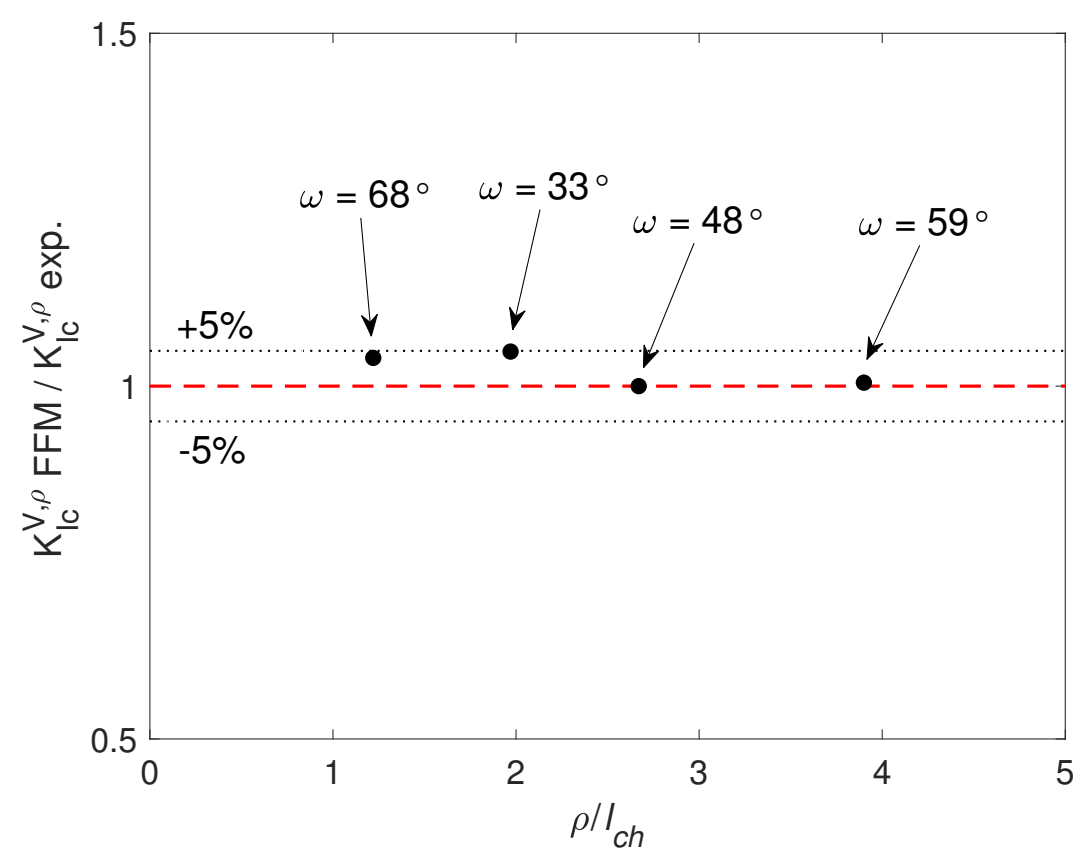

Figure 5. Comparison between experimental (denoted by exp.) and Finite Fracture Mechanics (FFM) apparent generalized fracture toughness for the considered nano-cantilevers. The ratio is plotted against the dimensionless notch root radius.

Table 4. Comparison between experimental (denoted by exp.) and FFM apparent generalized fracture toughness $\left(\mathrm{MPa} \mathrm{m}^{1-\lambda}\right)$ for the considered nano-cantilevers. For the sake of clarity, dimensionless values of the notch root radius are reported as well, where $l_{c h}=\left(K_{I c} / \sigma_{u}\right)^{2} \approx 5.18 \mathrm{~nm}$.

\begin{tabular}{ccccc}
\hline$\omega(\mathrm{deg})$ & $\rho / l_{c h}$ & $\boldsymbol{K}_{I c}^{V}$ & $\boldsymbol{K}_{I c}^{V, \rho}$ FFM & $\boldsymbol{K}_{I c}^{V, \rho}$ exp. \\
\hline 33 & 1.97 & 1.04 & 1.50 & 1.43 \\
48 & 2.67 & 1.08 & 1.70 & 1.70 \\
59 & 3.90 & 1.15 & 2.05 & 2.04 \\
68 & 1.22 & 1.25 & 1.56 & 1.50 \\
\hline
\end{tabular}

\section{Discussion}

The results presented in Section 3 clearly show that the FFM is able to characterize the fracture process of single crystal silicon nanoscale samples. The main advantage of the approach is that, similarly to the TCD [30], it can easily handle notched and cracked geometries. Difficulties in realizing accurate cracks, when dealing with ideal brittle fracture, are indeed well-known and could result in apparent scale dependent fracture toughness. Figure 3 clearly shows that also for a very small notch radius, the apparent generalized fracture toughness deviates from the sharp case. This means that small notch radii cannot be assumed or simplified as sharp. This mistake is commonly made when the FIB processing system (or chemical etching) is used to directly introduced a crack-like notch, based on the assumption that for a small $\rho / a$ ratio the geometry could be treated as a crack. Unfortunately, 
this assumption does not hold at a very small scale for ideal brittle materials such as the single crystal silicon, that would require, ideally, an atomically sharp crack (ideal Griffith's crack) [22] to determine the proper constant and scale independent fracture toughness. The FFM approach proposed here, instead, provides directly the generalized apparent fracture toughness and gives the possibility to handle different notch radii and opening angles. This conclusion is supported by Figure 5, where the failure assessment is reliable for all the geometries, with negligible differences.

FFM is added therefore to the list of methods that have been proven to be successful when applied at small scale, such as the TCD [30] and the strain energy density [17]. Indeed, these methods share several similarities. Strain energy density and FFM have the same proportionality between the critical notch stress intensity factor and the two fundamental properties i.e., the fracture toughness and the ultimate tensile strength. The difference is that in the FFM the relation depends on notch opening angle only, while in the strain energy density it depends on Poisson's ratio as well [51]. TCD and FFM, instead, both rely on the definition of a critical length scale parameter. While according to the TCD the critical distance is a material constant, the FFM critical crack advancement $l_{c}$ depends both on the notch radius and amplitude [33]. Figure 4 shows that when the notch radius tends to large values, i.e., smooth samples, all the curves converge towards the same constant value. In this case, the energy requirement provides a constant crack advancement in agreement with the quantized fracture mechanics (QFM) [52], while the stress condition reduces to $\sigma=\sigma_{u}$ and determines the final failure. When the notch radius tends to zero, the geometry reverts to the sharp V-notch case: In the crack case $\left(\omega=0^{\circ}\right)$, the energy balance reverts to $K_{I}=K_{I c}$ and governs the failure mechanism, while the stress requirement leads to the constant critical crack advancement related to the TCD line method [36].

Generally speaking, for all the methods based on a length parameter, the latter can be related to Irwin's length $l_{c h}=\left(K_{I c} / \sigma_{u}\right)^{2}$, with $l_{c h} \approx 5.18 \mathrm{~nm}$ in the present work. Recalling the synthesis by means of the TCD presented in $[30,36]$, it could be asserted that all the critical distances are proportional to [53]:

$$
\bar{l}_{c}=\frac{1}{\pi}\left(\frac{K_{I c}}{\sigma_{u}}\right)^{2}=\frac{1}{\pi} l_{c h}
$$

By substituting numerical values in Equation (14), a critical length $\bar{l}_{c} \approx 1.65 \mathrm{~nm}$ is obtained. This value obviously agrees with the critical distance evaluated experimentally in [30] i.e., $\approx 1.3-1.9 \mathrm{~nm}$, and it is very close to the critical singular stress field length of $1.5-3 \mathrm{~nm}$ at which the continuum-based LEFM breaks down, i.e., $4-5$ times the fracture process zone of $0.4-0.6 \mathrm{~nm}[15,17,22]$. Interestingly, all the crack advancements presented in Table 3 are well far from the fracture process zone size. Generalizing, Figure 4 shows that $l_{c}$ can only vary in a range of $\approx 0.45-0.65 l_{c h}$, i.e., $2.3-3.4 \mathrm{~nm}$. Again, these values are larger than the fracture process zone size and the critical length. The results confirm that if that low limit is not reached, continuum-based FFM method is still valid, despite the small scale involved.

At a smaller scale, e.g., atomic scale, extension and generalization of the approach are possible. The FFM, as introduced earlier, is a coupled criterion, i.e., it requires two conditions to be full-filled, one based on stress and the other on energy considerations. The stress criterion could be developed by considering the virial stress, provided that it is accepted as a representation of the mechanical stress at the atomic scale as recently showed in [20], or by employing a traction vector-based stress recently proposed in [54]. The energy criterion, instead, could be defined based on interatomic potential energy as provided in some recent examples based on the energy release rate [22,23] and on the averaged strain energy density [17].

The analysis presented here is limited to mode I loading conditions and to ideal brittle material. In case of semi-brittle materials, experimental conditions could affect the elastic-plastic fracture toughness, and scale dependency of fracture properties may occur [32,55]. This aspect should be carefully considered to define proper mechanical properties and therefore failure conditions of semi-brittle materials. 


\section{Conclusions}

When approaching small scales, the validity of continuum-based LEFM methods is questioned. The present work sheds light on the applicability of the FFM approach by using experimental data available in the literature related to blunt $\mathrm{V}$-notched nano-cantilevers, made of single crystal silicon. The work, therefore, focuses on ideal brittle fracture and mode I loading condition. The main conclusions can be summarised as follows:

- The comparison with experimental tests shows that the FFM is able to predict the failure load of notched nano-cantilevers at the considered small scale (Figure 5). The agreement between experimental and theoretical apparent fracture toughness was excellent for all the opening angles and notch root radii considered, with a maximum discrepancy of $4.7 \%$.

- The validity of the FFM at the considered scale is due to the fact that the low limit of continuum-based LEFM is not yet reached. Indeed, the crack advancements obtained are larger than the fracture process zone of $0.4-0.5 \mathrm{~nm}$ evaluated by other authors (Figure 4 and Table 3 ).

- The critical length $\bar{l}_{c} \approx 1.65 \mathrm{~nm}$ agrees well with the critical distance and the singular stress field length available in the literature and at which continuum-based LEFM breaks down. The crack advancements obtained here are all well far from this value (Figure 4), further justifying the validity of the method.

- Moreover, for very small notch root radii, the apparent generalized fracture toughness deviates from the sharp case (Figure 3). The deviation is larger for small notch opening angles. When dealing with cracks, if attention is not paid in the realization of an ideally sharp crack-tip, an apparent size dependent fracture toughness may result from experimental tests.

- Based on the evidence presented in the current work, the FFM can be an extremely useful method to predict the static failure of micro and nanodevices made of ideal brittle materials. Further investigations should be done when dealing with semi-brittle materials.

- As further development, the extension of the method to the atomic scale is possible by substituting continuum stress and energy formulations with the virial stress and interatomic potential energy, respectively.

Author Contributions: Conceptualization, P.G.; investigation, P.G.; formal analyses, P.G. and A.S.; writing-original draft preparation, P.G. and A.S.; writing-review and editing, P.G. and A.S.; funding acquisition, P.G. All authors have read and agreed to the published version of the manuscript.

Funding: This research was funded by the Academy of Finland grant number 321244.

Acknowledgments: P.G. is grateful to T. Kitamura, T. Sumigawa (Kyoto University) and Y. Yan (East China University of Science and Technology) for their support during the realization of the experiments.

Conflicts of Interest: The authors declare no conflict of interest.

\section{References}

1. Sumigawa, T.; Kitamura, T. In-Situ Mechanical Testing of Nano-Component in TEM. In Transmission Electron Microscopy; Maaz, K., Ed.; IntechOpen: Rijeka, Hrvatska, 2012; pp. 355-380.

2. Dehm, G.; Jaya, B.; Raghavan, R.; Kirchlechner, C. Overview on micro- and nanomechanical testing: New insights in interface plasticity and fracture at small length scales. Acta Mater. 2018, 142, 248-282. [CrossRef]

3. Kheradmand, N.; Rogne, B.R.; Dumoulin, S.; Deng, Y.; Johnsen, R.; Barnoush, A. Small scale testing approach to reveal specific features of slip behavior in BCC metals. Acta Mater. 2019, 174, 142-152. [CrossRef]

4. Pippan, R.; Wurster, S.; Kiener, D. Fracture mechanics of micro samples: Fundamental considerations. Mater. Des. 2018, 159, 252-267. [CrossRef]

5. Fang, H.; Shiohara, R.; Sumigawa, T.; Kitamura, T. Size dependence of fatigue damage in sub-micrometer single crystal gold. Mater. Sci. Eng. A 2014, 618, 416-423. [CrossRef]

6. Shimada, T.; Kitamura, T. Fracture Mechanics at Atomic Scales. In Advanced Structured Materials; Altenbach, H., Matsuda, T., Okumura, D., Eds.; Springer International Publishing: Cham, Switzerland, 2015; Volume 64, pp. 379-396. [CrossRef] 
7. Kitamura, T.; Sumigawa, T.; Shimada, T.; Lich, L.V. Challenge toward nanometer scale fracture mechanics. Eng. Fract. Mech. 2018, 187, 33-44. [CrossRef]

8. Bitzek, E.; Kermode, J.R.; Gumbsch, P. Atomistic aspects of fracture. Int. J. Fract. 2015, 191, 13-30. [CrossRef]

9. Malitckii, E.; Remes, H.; Lehto, P.; Yagodzinskyy, Y.; Bossuyt, S.; Hänninen, H. Strain accumulation during microstructurally small fatigue crack propagation in bcc Fe-Cr ferritic stainless steel. Acta Mater. 2018, 144, 51-59. [CrossRef]

10. Horstemeyer, M.; Farkas, D.; Kim, S.; Tang, T.; Potirniche, G. Nanostructurally small cracks (NSC): A review on atomistic modeling of fatigue. Int. J. Fatigue 2010, 32, 1473-1502. [CrossRef]

11. Kupka, D.; Huber, N.; Lilleodden, E.T. A combined experimental-numerical approach for elasto-plastic fracture of individual grain boundaries. J. Mech. Phys. Solids 2014, 64, 455-467. [CrossRef]

12. Lee, G.H.; Chung, Y.J.; Na, S.M.; Beom, H.G. Atomistic investigation of the T-stress effect on fracture toughness of copper and aluminum single crystals. J. Mech. Sci. Technol. 2018, 32, 3765-3774. [CrossRef]

13. Sorensen, D.; Hintsala, E.; Stevick, J.; Pischlar, J.; Li, B.; Kiener, D.; Myers, J.C.; Jin, H.; Liu, J.; Stauffer, D.; et al. Intrinsic toughness of the bulk-metallic glass Vitreloy 105 measured using micro-cantilever beams. Acta Mater. 2020, 183, 242-248. [CrossRef]

14. Yan, Y.; Sumigawa, T.; Wang, X.; Chen, W.; Xuan, F.; Kitamura, T. Fatigue curve of microscale single-crystal copper: An in situ SEM tension-compression study. Int. J. Mech. Sci. 2020, 171, 105361. [CrossRef]

15. Shimada, T.; Ouchi, K.; Chihara, Y.; Kitamura, T. Breakdown of Continuum Fracture Mechanics at the Nanoscale. Sci. Rep. 2015, 5, 8596. [CrossRef] [PubMed]

16. Gallo, P.; Sumigawa, T.; Shimada, T.; Yan, Y.; Kitamura, T. Investigation into the Breakdown of Continuum Fracture Mechanics at the Nanoscale: Synthesis of Recent Results on Silicon. In Proc. First Int. Conf. Theor. Appl. Exp. Mech.; Gdoutos, E.E., Ed.; Springer International Publishing: Cham, Switzerland, 2019; pp. 205-210. [CrossRef]

17. Gallo, P.; Hagiwara, Y.; Shimada, T.; Kitamura, T. Strain energy density approach for brittle fracture from nano to macroscale and breakdown of continuum theory. Theor. Appl. Fract. Mech. 2019, 103, 102300. [CrossRef]

18. Liu, F.; Tang, Q.; Wang, T.C. Intrinsic Notch Effect Leads to Breakdown of Griffith Criterion in Graphene. Small 2017, 1700028, 1-8. [CrossRef]

19. Sumigawa, T.; Ashida, S.; Tanaka, S.; Sanada, K.; Kitamura, T. Fracture toughness of silicon in nanometer-scale singular stress field. Eng. Fract. Mech. 2015, 150, 161-167. [CrossRef]

20. Gallo, P. On the Crack-Tip Region Stress Field in Molecular Systems: The Case of Ideal Brittle Fracture. Adv. Theory Simulations 2019, 2, 1900146. [CrossRef]

21. Singh, G.; Kermode, J.R.; De Vita, A.; Zimmerman, R.W. Validity of linear elasticity in the crack-tip region of ideal brittle solids. Int. J. Fract. 2014, 189, 103-110. [CrossRef]

22. Sumigawa, T.; Shimada, T.; Tanaka, S.; Unno, H.; Ozaki, N.; Ashida, S.; Kitamura, T. Griffith Criterion for Nanoscale Stress Singularity in Brittle Silicon. ACS Nano 2017, 11, 6271-6276. [CrossRef]

23. Huang, K.; Shimada, T.; Ozaki, N.; Hagiwara, Y.; Sumigawa, T.; Guo, L.; Kitamura, T. A unified and universal Griffith-based criterion for brittle fracture. Int. J. Solids Struct. 2017, 128, 67-72. [CrossRef]

24. Yin, H.; Qi, H.J.; Fan, F.; Zhu, T.; Wang, B.; Wei, Y. Griffith criterion for brittle fracture in graphene. Nano Lett. 2015, 15, 1918-1924. [CrossRef] [PubMed]

25. Huang, K.; Sumigawa, T.; Kitamura, T. Load-dependency of damage process in tension-compression fatigue of microscale single-crystal copper. Int. J. Fatigue 2020, 133, 105415. [CrossRef]

26. Gallo, P.; Sumigawa, T.; Kitamura, T.; Berto, F. Static assessment of nanoscale notched silicon beams using the averaged strain energy density method. Theor. Appl. Fract. Mech. 2018, 95, 261-269. [CrossRef]

27. Gallo, P.; Sumigawa, T.; Kitamura, T. Experimental characterization at nanoscale of single crystal silicon fracture toughness. Frat. Ed Integrità Strutt. 2019, 13, 408-415. [CrossRef]

28. Taylor, D. The Theory of Critical Distances: A link to micromechanisms. Theor. Appl. Fract. Mech. 2017, 90, 228-233. [CrossRef]

29. Susmel, L.; Taylor, D. The theory of critical distances to predict static strength of notched brittle components subjected to mixed-mode loading. Eng. Fract. Mech. 2008, 75, 534-550. [CrossRef]

30. Gallo, P.; Yan, Y.; Sumigawa, T.; Kitamura, T. Fracture Behavior of Nanoscale Notched Silicon Beams Investigated by the Theory of Critical Distances. Adv. Theory Simulat. 2018, 1, 1700006. [CrossRef] 
31. Ando, T.; Li, X.; Nakao, S.; Kasai, T.; Tanaka, H.; Shikida, M.; Sato, K. Fracture toughness measurement of thin-film silicon. Fatigue Fract. Eng. Mater. Struct. 2005, 28, 687-694. [CrossRef]

32. Saxena, A.K.; Brinckmann, S.; Völker, B.; Dehm, G.; Kirchlechner, C. Experimental conditions affecting the measured fracture toughness at the microscale: Notch geometry and crack extension measurement. Mater. Des. 2020, 108582. [CrossRef]

33. Liu, Y.; Deng, C.; Gong, B. Discussion on equivalence of the theory of critical distances and the coupled stress and energy criterion for fatigue limit prediction of notched specimens. Int. J. Fatigue 2020, 131, 105326. [CrossRef]

34. Leguillon, D. Strength or toughness? A criterion for crack onset at a notch. Eur. J. Mech. A/Solids 2002, 21, 61-72. [CrossRef]

35. Carpinteri, A.; Cornetti, P.; Pugno, N.; Sapora, A.; Taylor, D. A finite fracture mechanics approach to structures with sharp V-notches. Eng. Fract. Mech. 2008, 75, 1736-1752. [CrossRef]

36. Carpinteri, A.; Cornetti, P.; Sapora, A. Brittle failures at rounded V-notches: A finite fracture mechanics approach. Int. J. Fract. 2011, 172, 1-8. [CrossRef]

37. Sapora, A.; Cornetti, P.; Carpinteri, A.; Firrao, D. An improved Finite Fracture Mechanics approach to blunt V-notch brittle fracture mechanics: Experimental verification on ceramic, metallic, and plastic materials. Theor. Appl. Fract. Mech. 2015, 78, 20-24. [CrossRef]

38. Mantič, V. Interface crack onset at a circular cylindrical inclusion under a remote transverse tension. Application of a coupled stress and energy criterion. Int. J. Solids Struct. 2009, 46, 1287-1304. [CrossRef]

39. Felger, J.; Rosendahl, P.; Leguillon, D.; Becker, W. Predicting crack patterns at bi-material junctions: A coupled stress and energy approach. Int. J. Solids Struct. 2019, 164, 191-201. [CrossRef]

40. Yosibash, Z.; Mittelman, B. A 3-D failure initiation criterion from a sharp V-notch edge in elastic brittle structures. Eur. J. Mech. A/Solids 2016, 60, 70-94. [CrossRef]

41. Brochard, L.; Tejada, I.G.; Sab, K. From yield to fracture, failure initiation captured by molecular simulation. J. Mech. Phys. Solids 2016, 95, 632-646. [CrossRef]

42. Sapora, A.; Cornetti, P. Crack onset and propagation stability from a circular hole under biaxial loading. Int. J. Fract. 2018, 214, 97-104. [CrossRef]

43. Sapora, A.; Cornetti, P.; Campagnolo, A.; Meneghetti, G. Fatigue limit: Crack and notch sensitivity by Finite Fracture Mechanics. Theor. Appl. Fract. Mech. 2020, 105, 102407. [CrossRef]

44. Torabi, A.R.; Berto, F.; Sapora, A. Finite Fracture Mechanics Assessment in Moderate and Large Scale Yielding Regimes. Metals (Basel) 2019, 9, 602. [CrossRef]

45. Cornetti, P.; Sapora, A.; Carpinteri, A. Short cracks and V-notches: Finite Fracture Mechanics vs. Cohesive Crack Model. Eng. Fract. Mech. 2016, 168, 2-12. [CrossRef]

46. Cornetti, P.; Muñoz-Reja, M.; Sapora, A.; Carpinteri, A. Finite fracture mechanics and cohesive crack model: Weight functions vs. cohesive laws. Int. J. Solids Struct. 2019, 156-157, 126-136. [CrossRef]

47. Doitrand, A.; Estevez, R.; Leguillon, D. Comparison between cohesive zone and coupled criterion modeling of crack initiation in rhombus hole specimens under quasi-static compression. Theor. Appl. Fract. Mech. 2019, 99, 51-59. [CrossRef]

48. Gentieu, T.; Jumel, J.; Catapano, A.; Broughton, J. Size effect in particle debonding: Comparisons between finite fracture mechanics and cohesive zone model. J. Compos. Mater. 2019, 53, 1941-1954. [CrossRef]

49. Filippi, S.; Lazzarin, P.; Tovo, R. Developments of some explicit formulas useful to describe elastic stress fields ahead of notches in plates. Int. J. Solids Struct. 2002, 39, 4543-4565. [CrossRef]

50. Sapora, A.; Cornetti, P.; Carpinteri, A. Cracks at rounded V-notch tips: An analytical expression for the stress intensity factor. Int. J. Fract. 2014, 187, 285-291. [CrossRef]

51. Lazzarin, P.; Campagnolo, A.; Berto, F. A comparison among some recent energy- and stress-based criteria for the fracture assessment of sharp V-notched components under Mode I loading. Theor. Appl. Fract. Mech. 2014, 71, 21-30. [CrossRef]

52. Pugno, N.M.; Ruoff, R.S. Quantized fracture mechanics. Philos. Mag. 2004, 84, 2829-2845. [CrossRef]

53. Cicero, S.; Fuentes, J.; Procopio, I.; Madrazo, V.; González, P. Critical Distance Default Values for Structural Steels and a Simple Formulation to Estimate the Apparent Fracture Toughness in U-Notched Conditions. Metals (Basel) 2018, 8, 871. [CrossRef] 
54. Yang, J.; Komvopoulos, K. A stress analysis method for molecular dynamics systems. Int. J. Solids Struct. 2020. [CrossRef]

55. Wang, Y.; Fritz, R.; Kiener, D.; Zhang, J.; Liu, G.; Kolednik, O.; Pippan, R.; Sun, J. Fracture behavior and deformation mechanisms in nanolaminated crystalline/amorphous micro-cantilevers. Acta Mater. 2019, 180, 73-83. [CrossRef] 